\title{
Tobacco: An accepted pandemic?
}

\author{
Cornel Radu-Loghin
}

Motto': '... tobacco use is unlike other threats to global health. Infectious diseases do not employ multinational public relations firms. There are no front groups to promote the spread of cholera. Mosquitoes have no lobbyists'.

It has been known for over 400 years that tobacco use is 'A custome lothsome to the eye, hatefull to the nose, harmefull to the braine, dangerous to the lungs, and in the blacke stinking fume thereof, neerest resembling the horrible stigian ${ }^{2}$ smoke of the pit that is bottomelesse ${ }^{3}$.' In all these years it has been scientifically proved that tobacco consumption is the leading cause of preventable death. This is already a slogan often used in the medical world, so often that sometimes it goes unnoticed. So, year after year, we have reached the situation where at present $27 \%$ of all cancers are attributed to tobacco use ${ }^{4}$.

There are only few countries where politicians have reached a sufficiently high level of understanding and/or acceptance of the relationship between the money from tobacco taxes that fuels national budgets and the health of citizens they represent by the functions they have. In many other countries, tobacco control policies are manipulated or even controlled by the tobacco industry. The wolf guarding the sheep.

The tobacco industry's arguments as 'big taxpayers' to national budgets are totally false for at least two reasons:

1. That money does not come from industry but from citizens who consume tobacco products. If they did not consume those products, the money would no longer be 'burned' but used for healthier, better purposes such as a healthier diet, education, and culture. The taxes would of course be collected by the state in this situation as well.

2. When declaring themselves 'big taxpayers' those in the tobacco industry 'forget' to mention the burden caused in health systems by the products they sell. Treating diseases caused by tobacco (cancer, cardiovascular, lung, etc.) involves very high costs for health systems.

\section{Where is the money? When will this deadly industry really pay for the damages they have caused? ${ }^{5}$}

At the same time, globally, the tobacco control community bases its activities on totally insufficient resources compared to the scale of the disaster caused by tobacco. Worldwide more than 7 million deaths per year are caused by tobacco consumption. If the pattern all over the globe does not change, more than 8 million people a year will die from diseases related to tobacco use by $2030^{6}$. For comparison, the COVID-19 pandemic caused less than 4 million deaths in more than a year (March 2020 - June 2021) ${ }^{7}$ and the amounts invested in combating this pandemic and its effects are astronomical.
AFFILIATION

1 European Network for Smoking and Tobacco Prevention, Brussels, Belgium

CORRESPONDENCE TO

Cornel Radu-Loghin. European

Network for Smoking and Tobacco Prevention, Chaussee d'Ixelles 144, 1050, Brussels, Belgium. E-mail: cornel.radu@ensp.org ORCID ID: https://orcid.org/00000002-9922-4535

KEYWORDS

tobacco, pandemic

Received: 6 September 2021 Accepted: 21 September 2021 


\section{What are we heading for? How many more people have to die from tobacco use so that politicians tip the scales in favor of public health?}

ENSP has included since 2011 in its Statutes ${ }^{8}$ the objective to reduce the prevalence of tobacco use in Europe to less than $5 \%$ by 2040 . This objective was reiterated and strengthened in 2017 by the Athens Declaration 9 and after 10 years, in 2021, the European Commission included in Europe's Beating Cancer Plan the same goal of creating a tobacco-free generation in Europe, where less than $5 \%$ of people use tobacco by $2040^{10}$.

\section{Is this the moment of truth? Did the European Union's decision-makers finally understand the true dimension of the tobacco pandemic?}

In the coming years we will find the answer to all the above questions ...

\section{REFERENCES}

1. Zeltner T, Kessler DA, Martiny A, Randera F. Tobacco Company Strategies to Undermine Tobacco Control Activities at the World Health Organization: Report of the Committee of Experts on Tobacco Industry Documents. World Health Organization; 2000. Accessed September 6, 2021. http://www.who.int/tobacco/en/who_inquiry.pdf

2. Stygian. Wikipedia, The Free Encyclopedia. Updated September 8, 2021. Accessed September 6, 2021. https:// en.wikipedia.org/wiki/Stygian

3. A Counterblaste to Tobacco. Published 1604. Accessed September 6, 2021. http://www.laits.utexas.edu/ poltheory/james/blaste/blaste.html

4. European Commission. World No Tobacco Day 2021: Statement by Health and Food Safety Commissioner Stella Kyriakides. STATEMENT/21/2761. May 31, 2021. Accessed September 6, 2021. https://ec.europa.eu/ commission/presscorner/detail/en/statement_21_2761

5. Sy D. How can people living with NCDs make tobacco companies pay? Exposetobacco. May 26, 2021. Accessed September 6, 2021. https://exposetobacco.org/resource/ ncd-tobacco-liability/

6. Center for Diseases Control and Prevention. Fast facts. Updated June 2, 2021. Accessed September 6, 2021. https://www.cdc.gov/tobacco/data_statistics/fact_ sheets/fast_facts/index.htm

7. World Health Organization. WHO Coronavirus (COVID-19) Dashboard. Accessed September 6, 2021. https://covid19.who.int/

8. European Network for Smoking and Tobacco Prevention. European Network for Smoking and Tobacco Prevention: Statutes. Accessed September 6, 2021. http://ensp.
network/wp-content/uploads/2016/07/ENSPstatutes-2011.pdf

9. Athens Declaration. European Network for Smoking and Tobacco Prevention. May 26, 2017. Accessed September 6, 2021. http://ensp.network/athens-declaration/

10. European Commission. Public Health: EU Tobacco Products Directive is delivering but stronger action is needed. May 20, 2021. Accessed September 6, 2021. https://ec.europa.eu/commission/presscorner/detail/ en/ip_21_2563

\section{CONFLICTS OF INTEREST}

The author has completed and submitted the ICMJE Form for Disclosure of Potential Conflicts of Interest and none was reported.

\section{FUNDING}

There was no source of funding for this research.

ETHICAL APPROVAL AND INFORMED CONSENT

Ethical approval and informed consent were not required for this study.

DATA AVAILABILITY

Data sharing is not applicable to this article as no new data were created.

PROVENANCE AND PEER REVIEW

Not commissioned; internally peer reviewed. 